\title{
Gamifying learning for learners
}

\author{
Christo Dichev ${ }^{*}$ (D), Darina Dicheva and Keith Irwin
}

\author{
* Correspondence: dichevc@wssu. \\ edu \\ Winston-Salem State University, \\ Winston Salem, NC 27110, USA
}

\begin{abstract}
The majority of user models in gamification are based on user's gamer personality. However, the motivations driving individuals' learning behavior differ from their motivations when playing. There is no evidence that learners' experiences in gamified activities are described by these models. Thus, an alternative model capturing learners' motivational experiences and relating them to the motivational mechanisms of gamification design is needed. To fill this gap we propose a contextspecific typology which groups learners based on their type of motivation and perceived ability associated with a learning activity. The purpose of this proposal is to provide a framework for connecting each learner's type to a set of motivational affordances to which that type is susceptible. Facilitating the task of selecting motivational affordances matching learner's type aids the design of customized gamified learning.

Keywords: Educational gamification, Learners types, Motivational design
\end{abstract}

Gamification has emerged as a design strategy to enhance user motivation (Dicheva, Dichev, Agre, \& Angelova, 2015). Educational gamification, in particular, aims at designing interventions that make learning activities more engaging and meaningful to the learners. However, gamification designers have often been criticized for using certain pre-existing patterns of design elements with presumed motivational effects, regardless of the contexts of use (Alahäivälä \& Oinas-Kukkonen, 2016; Deterding, Dixon, Khaled, \& Nacke, 2011; Hamari, Koivisto, \& Sarsa, 2014).

Gamification of learning typically targets learning activities (e.g. participating in discussion forums, practicing problem solving, attending lectures, etc.) aiming to motivate desirable behavioral or learning outcomes. It is commonly agreed that the contextual factors are critical for designing gamified systems that support actual learners' needs (Alahäivälä \& Oinas-Kukkonen, 2016; Richards, Thompson, \& Graham, 2014). (The term "gamified systems" is used to refer to systems employing game elements to evoke game-like experience with the purpose to accomplish predefined goals). For learners, motivation to engage and persist in an activity stems from different sources, a significant one of which is the learning activity itself. Learning activities are characterized by features with positive impact on learners' motivation (motivators), such as acquiring useful skills or engaging with interesting problems, as well as by features with negative impact on their motivation (de-motivators), such as boring content or a high level of

(c) The Author(s). 2020 Open Access This article is licensed under a Creative Commons Attribution 4.0 International License, which permits use, sharing, adaptation, distribution and reproduction in any medium or format, as long as you give appropriate credit to the original author(s) and the source, provide a link to the Creative Commons licence, and indicate if changes were made. The images or other third party material in this article are included in the article's Creative Commons licence, unless indicated otherwise in a credit line to the material. If material is not included in the article's Creative Commons licence and your intended use is not permitted by statutory regulation or exceeds the permitted use, you will need to obtain permission directly from the copyright holder. To view a copy of this licence, visit http://creativecommons.org/licenses/by/4.0/. 
difficulty. To account for these contextual factors, we proposed the Activity-Centered Gamification Design (ACGD) approach (Dichev, Dicheva, \& Irwin, 2019), which puts the emphasis of the design process on the activity to be gamified. ACGD involves identifying the motivators and de-motivators and selecting motivational affordances congruent with the motivational drivers and barriers which learners experience in a particular gamified activity. This adds a contextual component to the gamification design. The term gamification design is used here to refer to the adopted methods for deciding what, when, and how to incorporate game elements for affording gameful motivating experiences (Landers et al, 2018) in non-game contexts. Drawing on the growing understanding that in the gamification design both the context of use and the qualities of the users should be recognized (Alahäivälä \& Oinas-Kukkonen, 2016; Hamari et al., 2014), we propose to enrich the ACGD framework by making it learner-specific. This acknowledges the fact that learners perceive learning activities differently depending on the perceived activity values and their perceived abilities. The identified earlier motivators capture the perceived activity values. However, learners' decision on whether and how to engage in certain learning activities depends also on the perceived effort of that engagement.

To address this limitation, we supplement ACGD with a typology segmenting learners in groups, which respond differently to gamified learning activities. Creating learner typologies is a largely unexplored approach for understanding what motivates learners to engage in gamified activities. The proposed typology categorizes learners based on their motivational and ability-related characteristics. Self-Determination Theory (SDT) (Ryan \& Deci, 2000) and Expectancy-Value Theory (EVT) (Eccles, 1983) provide the theoretical background for the typology. According to SDT, human behavior is driven by internal (intrinsic) and external (extrinsic) motivation. EVT posits that students' choices and persistence in a task are determined by the expectancies for success and subjective task values. From a more general perspective, Michie, van Stralen, and West (2011) found that motivation and capability are prerequisite for performing volitional behavior. Accordingly, our typology groups learners based on their perception of two aspects associated with a learning activity, namely, the perceived motivational drivers and the perceived attainability of the activity goals (e.g. the perceived availability of mental or physical resources for achieving the goals). It builds on the fact that some learners may see the gamified activity more as a game and others more as a learning task. Yet, different individuals may perceive the same activity in a different way: as too difficult, too easy, boring, interesting, unachievable, rewarding, etc., which influences their subsequent behavior. Meaningful engagement in a gamified activity entails an appropriate level of perceived ability balanced with appropriate motivation.

The purpose of the proposed typology is to provide a framework for connecting each learner's type to a set of motivational affordances to which that type is susceptible. The majority of models intended to explain user preferences for game design elements are focusing on users' gamer personalities (Mora et al., 2019). There is no evidence, however, that learners experience game elements incorporated in learning activities in the way defined by these models. Recognizing this gap and the need for customization, we propose a typology reflecting differences in learners' experiences and attitudes towards gamified activities. 


\section{Related work}

In recent years, researchers have started studying how gamification affects different groups of individuals with common characteristics or behaviors, focusing mainly on player types. A number of models of gamer psychology have been proposed and debated. Bartle's model (Bartle, 1996; Bartle, 2005) was the earliest attempt to break down players' psychological responses in a multiplayer game. Bartle identified four player types: Achiever (works for mastery), Explorer (works for discovery), Socialiser (works for social status), and Killer (works to win). Yee (2015) expanded this typology and proposed a model describing three central motivations, with ten sub-components: Achievement (advancement, mechanics, competition), Social (socializing, relationship, teamwork), and Immersion (discovery, role-playing, customization, escapism). However, both of these models focus on specific game genres. The demographic game design models (DGD1, DGD2) (Bateman \& Boon, 2006; Bateman, Lowenhaupt, \& Nacke, 2011) were intended for player preferences that cater for different demographic groups. By adapting the Myers-Briggs typology (Myers, 1962) to games, they propose four play styles: Wonderer, Conqueror, Manager, and Participant. From a slightly broader perspective, Ferro, Walz, and Greuter (2013) divided the players into five categories: Dominant, Objectivist, $\mathrm{Hu}$ manist, Inquisitive, and Creative based on the similarities between personality models and player types. The BrainHex model (Nacke, Bateman, \& Mandryk, 2014) combined previous research on player types and neurobiological insights of player satisfaction. The model presents seven archetypes of players: Seeker, Survivor, Daredevil, Mastermind, Conqueror, Socializer, and Achiever. While these models are used in personalizing gamified systems, they were built for game design and their usefulness for gamification design is limited.

Differently, Marczewski (2015) introduced the Hexad framework of gamification user types to assess individuals' preferences for game elements in the context of gamification. It builds on Bartle's player types, taking into account players' intrinsic and extrinsic motivation. The framework categorizes the styles of interaction with gamified systems according to six types: Philanthropists (motivated by purpose), Socialisers (motivated by relatedness), Free spirits (motivated by autonomy), Achievers (motivated by competence), Players (motivated by rewards), and Disruptors (motivated by triggering of change). Tondello et al. (2016) tested the correlation of each Hexad user type with 32 game elements commonly used in gamification and suggested that Hexad can be used as a model to personalize user experience. Further, they created a 24-item questionnaire based on the Hexad framework to assess individuals' preferences for game elements and later validated the proposed scale (Tondello, Mora, Marczewski, \& Nacke, 2018). The studies related to the Hexad framework in a gamification context were paralleled by such in the area of persuasive technology. For example, Orji, Tondello, and Nacke (2018) showed significant relationships between the Hexad user types and different strategies employed in persuasive technologies. However, Hexad typology was built with a general gamification user in mind and does not reflect the motivational specifics driving learners in educational environments. Moreover, the studies exploring player (player-derived) type models typically analyze the relationship between player types and players' self-reported preferences to game elements without considering players' experience in real gamified environments (Lopez \& Tucker, 2019). While such studies contribute towards understanding the mechanisms of tailored gamification, they are too abstract. In contrast, our typology emerged from practical observation of learner behaviors in gamified environments. 
Lopez and Tucker (2019) did conduct a case study on Hexad player types in an educational context, using a gamified classroom response system (Kahoot). The study revealed that in general students' perception of the game elements is associated with their Hexad player type. However, the study targeted a rather specific and simple activity - responding with a clicker in class, which doesn't require strong motivation. In addition, the selected in the study answer anonymity reduces the psychological restraints of responding. Similar simple actions are more amenable to evoking gamer personalities than more demanding learning tasks.

Games are intrinsically valued activities. Therefore, gamers are motivated to play for the activity itself and not for any separate rewards. Earning rewards is considered as "fringe benefits" and the core reason to play is the experience of the play itself (Amr, 2012). Educational activities, on the other hand, are not intrinsically motivating for many learners. For such learners, the extrinsic benefits are the main drivers for engaging in educational activities. As learning requires effort and persistence, the quality of engagement depends also on the level of the required efforts, that is, the cost of engagement - a dimension largely missing in player or player-derived types. While our typology covers the segment of learners framing learning activities as a kind of game the cluster of learners not perceiving the fun in the gamified activities cannot be captured adequately by the extant gamer typologies.

Closest to our work is that of Barata, Gama, Jorge, and Gonçalves (2017), who studied student performance and preferences to gamification elements in a gamified engineering course and identified four types related to the gamification preferences: Achievers, Regular, Half-hearted Students, and Underachievers. While Barata's grouping is related to educational gamification, it is based on experimental student clustering in a single, master-level course with gamified educational activities that were required and graded, thus mirroring the extrinsic drives of the current educational system. This entails that their proposed grouping is influenced by extrinsic rewards, namely grades. While reflecting the extrinsic motivation of learners, it doesn't capture adequately the influence of intrinsic motivation on students' behavior in educational activities. The proposed here typology fills this gap. Based on the Self-Determination Theory, it considers the entire motivational specter: from intrinsic motivation, to extrinsic motivation, to a-motivation. While Barata's gamification types are covered by the proposed typology, it also includes types that are not readily discernible in Barata's clustering. In addition, unlike our proposal, Barata's clustering does not yield descriptive characteristics enabling identification of learners belonging to different groups for predicting their preferences for game elements, which can support personalization of the gamification experiences in new situations.

A number of studies show that the effects of gamification vary significantly among participating learners (Barata et al., 2017; Fitz-Walter, Johnson, Wyeth, Tjondronegoro, \& Scott-Parker, 2017; Lister, West, Cannon, Sax, \& Brodegard, 2014; Rothrock \& Freivalds, 2018). Although several researchers (Hamari, Huotari, \& Tolvanen, 2015; Huotari \& Hamari, 2017; Nicholson, 2015; Rigby, 2014) have suggested that various contextual factors may modify gamification's impact, little has been explored yet with regard to how other factors, such as the activity importance, level of effort, learner self-efficacy, selfesteem, etc. may affect users' preferences for game elements. Instead, when selecting game elements intended to appeal to certain types of learners, designers still rely on player (or player-derived) typologies. The focus on players' type indicates an emphasis on the gameful aspects of the gamified systems. However, the results of our empirical studies on 
driving factors for learners' engagement in gamified activities suggest that the perceived gamefulness and the perceived utility of activities have different motivational effects on different groups of students (Dicheva, Irwin, \& Dichev, 2019). This adds to the observed above gap - the lack of typologies created specifically for the domain of educational gamification. We address these issues with the proposed simple typology.

\section{The proposed typology}

\section{Background}

Gamified learning systems can be viewed as utilitarian systems using a hedonicinspired design to motivate their use (Dicheva et al., 2019). In such systems, the hedonic values can be experienced through achieving specific utilitarian goals. If the ability or motivation of a particular learner for pursuing those goals is insufficient, then the hedonic aspects cannot be experienced, making a gamer typology irrelevant for predicting the behavior of that learner. In particular, the decision to engage in a gamified learning activity may depend on the perceived utilitarian benefits of that engagement (earning better grades, learning new skills) and the required efforts. We interpret ability and usefulness in terms of the Expectancy-Value Theory (Eccles, 1983; Wigfield \& Cambria, 2010). Ability is interpreted as the extent to which a learner is confident in their ability to succeed in an activity and usefulness as how useful or enjoyable the learner perceives the activity (activity values). The perceived usefulness and degree of effort may have effect on learners' preferences for some game elements (e.g., required effort for attaining a specific position on a leaderboard in relation to the personal value of being on that position). Thus, some learners may prefer badges earnable with little effort, while others may target badges earnable through completing interesting challenges. We hypothesize that for more demanding (requiring more effort/time) gamified learning activities, the predictive value of the perceived usefulness and attainability for engaging in them grows. In the remaining of the paper, the term ability is used in the sense of perceived ability referring to the perception of person's capability (used in a broader sense as resources that an individual might need) to perform a behavior.

The theoretical foundation of this typology are the Self-Determination Theory (SDT) and Expectancy-Value Theory (EVT). These theories provide alternative explanations of why people engage in specific behavior. SDT postulates that the goal-directed behavior is triggered by two types of motivation: intrinsic motivation (making volitional choices while meeting one's needs of autonomy, competence, and relatedness) and extrinsic motivation (doing something for separable outcomes). Intrinsic motivation is observed when one engages in an activity out of genuine interest and is truly selfdetermined, in contrast with extrinsic motivation where one does that for external incentives such as grades. However, extrinsic motivation could also be used as a means to influence learners' behavior and foster engagement without negatively impacting their intrinsic motivation. The initial goal of the learner is often extrinsic to the activities in a gamified system and thus extrinsic motivation is what initially makes the learners choose to engage with the system. However, this can be used to promote internalized form of extrinsic motivation. Internalization is a process where the external regulation of a behavior is transformed into an internal regulation and thus no longer requires the presence of an external contingency (Ryan \& Deci, 2000). According to 
EVT, the motivation is a function of the expectation of success and perceived value. Expectation refers to individual's belief about their ability to perform certain tasks, whereas task values refer to how useful or enjoyable the learner perceives the task. In both theories the motivation of engagement depends on the perceived value of that engagement. In SDT the value can result from intrinsic motivation or extrinsic motivation. In EVT the value can arise from intrinsic interest or perceived utility (usefulness) of the activity. These correspondences provide basis for integration - the intrinsic interest and utility values from EVT can be integrated with the conceptually similar intrinsic and extrinsic motivators from SDT. Such conceptual integration suggests in turn typifying learners along two dimensions: the first one reflecting intrinsically and extrinsically motivated types, the second one reflecting the perceived ability for success. As both motivation and ability-related perspectives are deciding factors in educational context they are forming the two dimensions of the proposed two-dimensional typology. The motivational dimension reflects the intrinsic-extrinsic aspect from SDT integrated with the usefulness and intrinsic values from EVT. Experiences such as autonomy, competence, curiosity are on the intrinsic side of the motivation dimension, while grades, awards, praise, etc. are on the extrinsic side. The ability dimension reflects the perceived ability to succeed from EVT. Its two ends are low and high.

The differentiating features describing the suggested types are motivational. Notably, gamification is founded on the concept of motivational affordances (Zhang, 2008), described as interactions between learners and game elements that increase the motivation for learners to engage. The value of the proposed typology lies in this link. Learners' types can be used to identify the motivational affordances to which each type is susceptible. The selection of motivational affordances can be implemented as a function of a learner type taking into account the motivation and the perceived ability for that type.

\section{Learners gamification types}

In the present form, the proposed simple typology characterizes four main types of learners based on their motivators (intrinsic vs. extrinsic) and perceived abilities (high vs. low): Capable explorer, Struggling explorer, Capable benefit-seeker, and Struggling benefit-seeker. In reality, there is another type, Indifferent learners, which is also included for completeness (see Fig. 1). Here type represents a group of learners who, in a given activity, behave similarly based on their motivators and perceived abilities. The proposed model has potential for customizing gamified learning activities. It provides a framework for clustering learners based on the driving influences for engaging in learning activities which can be used for predicting learners' susceptibility to game elements. If we know motivators and de-motivators influencing the behavior of a particular group of learners, it is possible to choose motivational affordances more predictably, making the gamification meaningful (Nicholson, 2015) for that category of learners.

\section{Capable explorer}

I want to learn and I can. Learners of this type are naturally motivated to do their work because they feel learning itself is interesting and satisfying. They engage in activities simply for the enjoyment and satisfaction that comes from completing the activity (Deci, 1971; Deci, Koestner, \& Ryan, 2001). These learners typically seek experience, 


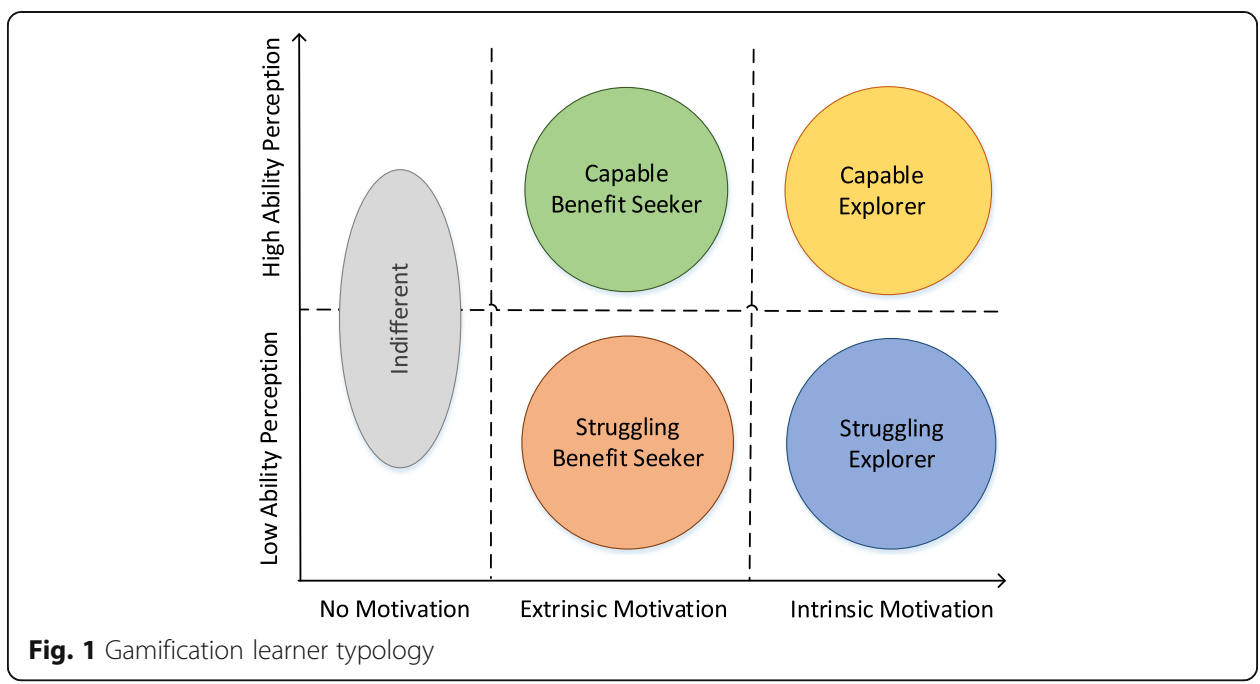

learning new things, solving problems, acquiring skills and developing competence perceiving that learning itself is the reward. They believe in themselves and in their abilities. They approach difficult tasks as challenges to be mastered rather than as threats to be avoided. Capable explorers are more likely to be susceptible to motivational affordances that support feeling of competence, mastery, autonomy, curiosity and achieving meaningful goals, together with support for scarcity, and social competition. They are less attracted by easily achievable awards and trivial challenges.

\section{Struggling explorer}

I want to learn and I strive. Similarly to Capable Explorers, learners of this type are driven by the desire to improve their competence by acquiring new knowledge and skills. However, they are less certain in their abilities. As a result, they tend to circumvent goals perceived as unattainable to avoid disappointments, which in turn may lead to lower levels of achievements. In line with EVT, the perceived weakness in their ability to successfully engage in some learning activities has to be balanced with stronger motivational pulls. Accordingly, gamification features with potential to reinforce motivational drives of this type of learners include those supporting feeling of competence, accomplishment, meaning, support for enhancing their self-efficacy and tracking their progress, as well as, support for goal setting and customization. This type of learners tends to not favor competitive environments and too challenging tasks.

\section{Capable benefit-seeker}

I do it for the grades and I succeed. Learners of this type are not really interested in the learning activity for its own sake, rather they expect their effort to be recognized with external outcomes, such as rewards and incentives. They tend to put out the amount of effort that provides the maximal gain. These learners normally engage in activities to earn good grades, please the instructor, or gain the admiration of peers. Since the behavior being rewarded may be internalized into a self-regulated and valued behavior (Ryan \& Deci, 2000), extrinsic motivation varies in the extent to which it has been internalized. Similarly to the Capable Explorers, the Capable Benefit-Seekers believe in 
themselves and in their abilities. Motivational affordances likely to appeal to them include those supporting feeling of attaining values separate from the activity, such as status, beneficial social comparison, achievements, badges, virtual goods, and incentives. More important, maintaining the inherently extrinsic but often internalized motivation through competence and autonomy facilitating features could promote self-determined learning behavior. This type of learners are less attracted by intrinsic goals.

\section{Struggling benefit-seeker}

I do it for the grades but I struggle. Learners of this type prefer easy work that focuses on obtaining acceptable grades to pass the requirements. They are not enthusiastic about gaining new knowledge or skills and often take little responsibility for their learning. Also, they try to complete learning activities without investing much effort. These learners typically experience low self-efficacy. As a result, they tend to avoid challenging tasks. Due to the low confidence in their ability, the learning activities are frequently perceived as difficult. In accordance with EVT, fostering the desired behavior for this type of learners entails reinforcement of their ability beliefs and perceived utility of the activity. This suggests, in turn, motivational affordances boosting their selfefficacy and persistence and raising the perceived value of engagement in the learning activities. The gamification features with likely positive effect on the targeted behavior of these learners include progress feedback, virtual economy, streaks, incentives, hints/ clues, power-ups/boosters, easy start, customization, and anonymity.

\section{Indifferent}

I don't care. In reality, there is another category, students indifferent to the educational gamification. These students are characterized by lacking any motivation to engage in the gamified learning activities caused by either perceiving no value in them or complete lack of competence. In general, indifferent students find neither intrinsic nor extrinsic benefits from gamified learning activities (McCoach \& Siegle, 2003). As a result, they lack incentives for interacting with the gamified system. According to SDT, motivation is characterized as continuum from a-motivation to extrinsic to intrinsic motivation, thus indifferent learners are positioned in Fig. 1 at the far left alongside the motivation axis. The lack of any motivational drive towards the gamified activities makes this type of learners not susceptible to the motivational affordances typically used in gamifying learning. A possible approach in this case is to consider extending the range of gamified activities and adding external rewards to them to foster participation that enables spurring learners' behavioral engagement. When successful, such an involvement can be used to nurture cognitive engagement.

As mapping individual learners onto game design elements is challenging (Tondello et al., 2016), the proposed typology is intended to serve as a simple two-dimensional model to facilitate learners' type mapping. Capable Explorers typically do not need external motivational reinforcement to engage in learning activities. Their interaction with the motivational affordances in the gamified activity is driven by intrinsic interests. As in the current educational system intrinsic motivation is often undermined by the heavy use of external motivators (Baranek, 1996), the proportion of intrinsically motivated learners, in general, is relatively low. For the Capable Benefit-Seekers, the level of 
motivation for engaging in gamified learning activities would depend on the perceived usefulness of the targeted external outcomes. Thus external motivational reinforcement will have a bigger effect for activities with targeted outcomes perceived by them with low importance.

The benefit of gamifying learning activities is less significant for Capable Explorers and Capable Benefit-Seekers as they will be generally successful regardless of whether the activity is gamified or not. Thus, the overall level of success of gamifying learning depends on how it improves the engagement of the Struggling Explorers and Struggling BenefitSeekers. These learners typically need external motivational reinforcement for meaningful involvement in the targeted activities. The proportionally larger Struggling Benefit-Seeker type includes extrinsically motivated learners with low self-efficacy, typically due to lack of skills, falling behind, conflict with other activities, etc. Cognitively demanding tasks, such as learning, require a level of motivation congruent to the category of learners. Challenges that are interesting and exciting for Capable Explorers may require hard work and extra effort for Struggling Benefit-Seekers and consequently additional sources of motivation. Therefore, when it is not possible to personalize a gamified system to the different types of users, it should be tailored with the largest group in mind. It is important to realize that ignoring the distinction between different types of learners can lead to misleading conclusions for the benefits of gamifying some learning activities.

\section{Supportive evidence}

The idea of the proposed here typology came out of our practical experiences and observations in gamifying a range of academic courses over the last four years. In this section we present some results that provide supportive evidence for the proposed typology. They combine empirical quantitative data with qualitative experiences.

In Fall 2017 we started a longitudinal study aimed at exploring certain relations between various motivational drivers and gamification. The study used the OneUp course gamification platform (Dicheva, Irwin, \& Dichev, 2018) for gamifying out-of-class student practicing in a Data Structures class. For the control group, the gamification features were turned off and OneUp was used only for practicing. The result showed a very low use of the practicing tool by the students, which was in line with observations from other authors (Beatty, Merchant, \& Albert, 2019; Loboda, Guerra, Hosseini, \& Brusilovsky, 2014). In the next phase of the study (Spring 2018), we enabled some gamification features in the OneUp platform for the experimental group, including avatars, badges, a leaderboard, a progress bar, and virtual currency. The use of the gamified version resulted in a significant increase in student out-of-class practicing (Dicheva, Irwin, \& Dichev, 2019a). We noticed that a significant proportion of the students were striving to accumulate virtual currency while a smaller proportion was targeting badges. These observations indicated that as a result of gamifying the practicing activity, its perceived usefulness has undergone a change across the participating students but not uniformly. For some students the usefulness included the benefit of earning virtual currency, for others - the fun of collecting badges. In OneUp the virtual currency earned through practicing is tradable for goods based on rules defined by the instructor. Thus, learners can spend their virtual currency to purchase some courserelated benefits, such as extending deadlines or re-submissions, which can help them mitigate some negative outcomes in the future. This way, virtual currency was used as 
an additional psychological factor (Hsee, Yu, Zhang, \& Zhang, 2003) linking the gameful experience to some perceived benefits of practicing. Since earning virtual currency evokes perception of benefits with positive impact on course outcomes, it is more extrinsic in nature. On the other hand, as badges offer recognition for achievements and support competence needs (one of the three fundamental psychological needs, as per $\mathrm{SDT}$ ), they also carry some intrinsic value. This supports the proposed grouping along the intrinsic-extrinsic dimension of the propose typology.

In order to gather further evidence for the factors contributing to the segmentation of learners, we conducted a focus group. The goal was to seek students' input about the driving reasons for their engagement in gamified practicing. Questions about the reason for using the gamified practicing tool and what prompted them to start or continue a practicing session were used as a basis for the discussion. Three focal reasons emerged from the data analysis: boost my grades, improve my learning, and experience gameful learning. For better understanding of how learning satisfaction, grade improvement, and gameful experiences influence the use of gamified practicing, a quantitative study was conducted in parallel with the focus group (Dicheva et al., 2019). The results were in line with the findings from the focus group. An interest in improving their course grade and in earning virtual currency was the most frequently reported reason for using OneUp. However, the questions related to the driving effect of the gameful experience for practicing also yielded positive responses. This clustering of answers into two groups - one indicating interest in gameful experience and the other in practical usefulness, confirms again the suggested segmentation along an intrinsic-extrinsic dimension.

Next, we examined the frequency of taking practice quizzes by dates (Dicheva et al., 2019). The distribution revealed peaks around the dates of the three course exams. The intensified use of practicing in these periods suggests that majority of learners perceive the gamified practicing tool as a beneficial way to improve their course outcomes. This is a further indication that the perceived extrinsic value of gamified practicing is a significant predictor for its usage.

In the Fall 2019 study we removed the virtual currency. Besides the badges, we offered duels and call-outs, which allow a student to send a challenge to another student or to the entire class. The idea was to increase the opportunity for learning driven by intrinsic motivation through the duels and class call-outs, which enable learners to engage in a fun competition. Somewhat surprisingly the interest to this type of gamified practicing was low. In contrast, in a gamified General Physics course (Spring 2019), which used only virtual currency, students demonstrated high interest in practicing. Our explanation was that unlike in games, the winning of duels/call-outs, so as to experience the fun, required significant investment and persistent learning efforts. On the other hand, there was no extrinsic value associated with that activity. Yet, some learners may felt uncomfortable to challenge their classmates in learning (non-game) environment. Therefore, from the viewpoint of the EVT the perceived usefulness and enjoyment from involving in duels/call-outs may have not been sufficiently motivating, especially, for learners with low confidence in their abilities to succeed in such activities. In comparison, activities in which learners can earn virtual currency and spend it for course-related benefits demonstrated higher level of engagement.

The aggregated results of the studies provide an empirical support that the intrinsic and extrinsic motivators are two significant factors clustering learners with respect to their drives to engage in gamified practicing. The first group perceives the usefulness of 
gamified learning as an activity with an intrinsic value (learning and gameful experience), while the second - as an activity with an extrinsic value (boosting grades).

Notably, within these groups we were able to identify distinct patterns of interactions with OneUp for students with different levels of perceived skills, which suggested further differentiation of the intrinsic-extrinsic grouping. These patterns were repeatedly observed in our studies during Spring 2018, Fall 2018, Spring 2019, and Fall 2019. We used the students' course performance as a proxy of their perceived abilities/skills to divide them into two groups - high performing (HP), scoring $\mathrm{B}+$ and above, and low performing (LP). We measured the usage intensity of OneUp (based on system logs) to identify the distribution of the usage between the two groups (see Fig. 2). We interpret the results as follows. As low performing students are typically able to exploit only the gamification features rewarding modest achievements, part of the values offered by gamification remain unattainable for them. This limits the fun aspect of practicing and subsequently the amount of interactions. Differently, for high-performing students most of the incentives are achievable, which makes their practicing more enjoyable and leads to gameful learning experience motivating higher engagement with the practicing tool.

To look from a slightly different angle, we processed the collected data related to the amount of student interactions in the data mining tool Weka (2020). We discretized the usage intensity data for the students (marked as 'A', 'B', 'C', and 'DF'-students, where 'A', 'B', ' $C$ ', ' $D$ ', and ' $F$ ' indicate their course grade) into 4 bins, which can be viewed as high, decent, moderate, and low levels of engagement, correspondingly. Figure 3 shows that the mass of DF-students (dark gray) are in the low-engagement (leftmost) bin while the largest proportion of A-students (blue) are in the high-engagement (rightmost) bin. But we also notice that the low-engagement bin holds a certain number of A-students. A likely reason is that for A-students the practicing activity was not challenging enough (insufficient intrinsic value) and after several sessions they decided to dedicate their time to other activities.

This is another confirmation of our proposition regarding the role of perceived intrinsic interest. These observations are in line with findings of some other researchers. For example, Bandura (1997) recognizes that the role of students' self-efficacy is positively related to their academic motivation and performance outcomes, while Abramovich, Schunn, and Higashi (2013) found that low achieving students responded to game elements that reward participation, but not to those that rewarded mastery.

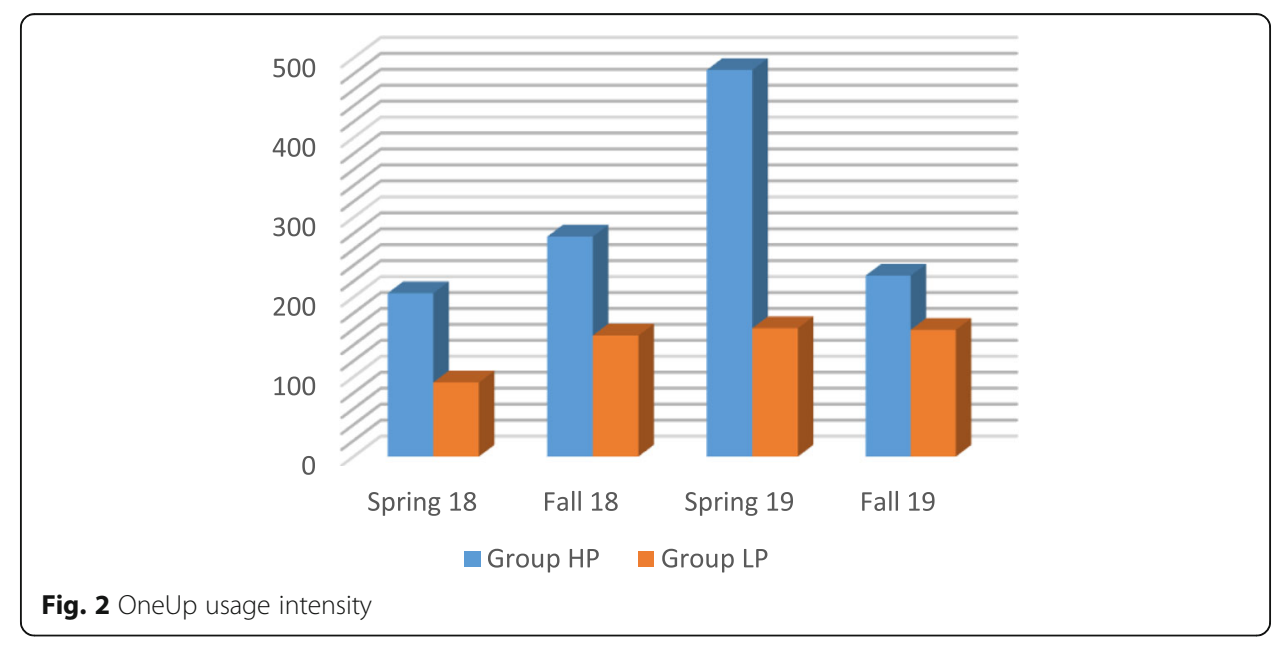




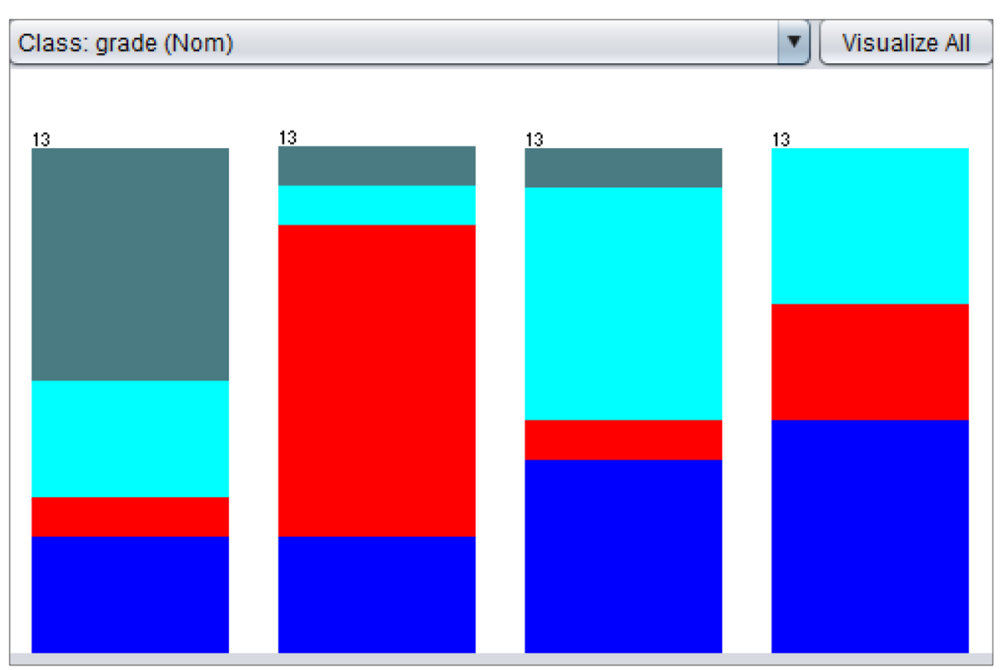

Fig. 3 Discretizing usage intensity data

The evidence collected in our studies shows that motivational drives and perceived ability-related characteristics do play a role in segmenting learners with respect to their engagement with gamified learning activities - a largely unexplored area of practical value. The consistent trend observed across the studies provides an empirical foundation for the proposed typology. A further validation is currently in progress.

\section{Conclusion}

Simply adding game elements to a learning activity and expecting improved motivation is overly optimistic. Achieving the desired outcomes entails understanding the broader context in which gamification is applied including both the learning activities and learners. A strategic step towards such understanding includes identifying the motivating and demotivating factors associated with the activities to be gamified and grouping the involved learners in meaningful motivation-based types. This approach, mostly missing in educational gamification, is addressed in this paper.

Learners involved in gamified activities have different motivations, abilities, and goals. It is unrealistic to believe that we can get learners to do something they are completely a-motivated to do or perceive themselves incapable of doing by gamifying it. As a step towards a learner-centered gamification design we propose a context-specific typology grouping learners with similar motivators and perceived abilities into five types. Rather than relying on a gamer's typology for gamifying learning activities, the proposed typology is shifting towards a gamification design guided by motivational theories of learning. The driving idea is that the motivational affordances used for gamifying learning activities should be selected based on the learners' intrinsic and extrinsic motivational drives and on the ability-related motivational experiences.

Knowing the motivational factors that positively or negatively impact the engagement of different groups of learners in an activity makes the outcome of motivational affordances' selection more predictive. Supportive evidence backing the proposed typology is discussed in the paper, while its further validation is in progress. 


\section{Authors' contributions}

CD Developed the typology and contributed to the related work and supportive evidence. DD Contributed to the supportive evidence and to the related work sections. KI contributed to the supportive evidence and managed the technical support of the work. The authors read and approved the final manuscript.

\section{Funding}

This material is based upon work funded by NSF Project HBCU-UP TIP 1623236 and NSF Project DUE-1821189. Any opinions, findings, and conclusions or recommendations expressed in this material are those of the author(s) and do not necessarily reflect the NSF's views.

\section{Availability of data and materials}

The datasets used and/or analyzed during the current study are available from the corresponding author on reasonable request.

\section{Competing interests}

The authors declare that they have no competing interests.

Received: 28 May 2020 Accepted: 20 August 2020

Published online: 08 October 2020

\section{References}

Abramovich, S., Schunn, C., \& Higashi, R. M. (2013). Are badges useful in education?: It depends upon the type of badge and expertise of learner. Educational Technology Research and Development, 61(2), 217-232.

Alahäivälä, T., \& Oinas-Kukkonen, H. (2016). Understanding persuasion contexts in health gamification: A systematic analysis of gamified health behavior change support systems literature. International Journal of Medical Informatics, 96, 62-70.

Amr, K. (2012). Learning through games: Essential features of an educational game PhD thesis, Syracuse University. URL: http:/ surface.syr.edu/idde_etd/56.

Bandura, A. (1997). Self-efficacy: The exercise of control. New York: Freeman.

Baranek, L. K. (1996). The effect of rewards and motivation on student achievement. (Master's thesis). Allendale, Michigan: Grand Valley State University.

Barata, G. S., Gama, S., Jorge, J., \& Gonçalves, D. (2017). Studying student differentiation in gamified education: A long-term study. Computers in Human Behavior, 71, 550-585.

Bartle, R. (1996). Hearts, clubs, diamonds, spades: Players who suit MUDs. Journal of MUD Research, 1(1). Retrieved on August 23, 2020, from http://www.mud.co.uk/richard/hcds.htm.

Bartle, R. (2005). Virtual worlds: Why people play. Massively Multiplayer Game Development, 2, 1.

Bateman, C., Lowenhaupt, R., \& Nacke, L. E. (2011). Player typology in theory and practice. In Proceedings of DiGRA 2011. Hilversum: The Netherlands.

Bateman, C. M., \& Boon R. (2006). 21st Century Game Design (game development series). Charles River Media.

Beatty, B. J., Merchant, Z., \& Albert, M. (2019). Analysis of student use of video in a flipped classroom. TechTrends, 63, 376-385. https://doi.org/10.1007/s11528-017-0169-1.

Deci, E. L. (1971). Effects of externally mediated rewards on intrinsic motivation. Journal of Personality and Social Psychology, 18(1), 105-115. https://doi.org/10.1037/h0030644.

Deci, E. L., Koestner, R., \& Ryan, R. M. (2001). Extrinsic rewards and intrinsic motivation in education: Reconsidered once again. Review of Educational Research, 71, 1-27. https://doi.org/10.3102/00346543071001001.

Deterding, S., Dixon, D., Khaled, R., \& Nacke, L. (2011). From game design elements to gamefulness: Defining "gamification". In Proceedings of the 15th international academic MindTrek conference: Envisioning future media environments. New York: MindTrek'11.

Dichev, C., Dicheva, D., \& Irwin, K. (2019). Towards activity-centered gamification design. In Proceedings of the 2019 IEEE international conference on teaching, assessment, and learning for engineering (TALE 2019). Yogyakarta: IEEE.

Dicheva, D., Dichev, C., Agre, G., \& Angelova, G. (2015). Gamification in education: A systematic mapping study. Educational Technology \& Society, 18(3), 75-88.

Dicheva, D., Irwin, K., \& Dichev, C. (2018). OneUp: Supporting practical and experimental gamification of learning. International Journal of Serious Games, 5(3), 5-21.

Dicheva, D., Irwin, K., \& Dichev, C. (2019). Exploring learners experience of gamified practicing: For learning or for fun? International Journal of Serious Games, 6(3), 5-21.

Dicheva, D., Irwin, K., \& Dichev, C. (2019a). OneUp: Engaging students in a gamified data structures course. In Proceedings of the 50th ACM technical symposium on computing science education (SIGCSE'19), (pp. 386-392). Minneapolis: ACM.

Eccles, J. (1983). Expectancies, values and academic behaviors. In J. T. Spence (Ed.), Achievement and achievement motives, (pp. 75-146). San Francisco: Freeman.

Ferro, L. S., Walz, S. P., \& Greuter, S. (2013). Towards personalised, gamified systems: An investigation into game design, personality and player typologies. In Proceedings of the 9th Australasian Conference on Interactive Entertainment: Matters of Life and Death - IE'13, 1-6. https://doi.org/10.1145/2513002.2513024.

Fitz-Walter, Z., Johnson, D., Wyeth, P., Tjondronegoro, D., \& Scott-Parker, B. (2017). Driven to drive? Investigating the effect of gamification on learner driver behavior, perceived motivation and user experience. Computers in Human Behavior, 71, 586-595. https://doi.org/10.1016/j.chb.2016.08.050.

Hamari, J., Huotari, K., \& Tolvanen, J. (2015). Gamification and economics. In S. P. Walz, \& S. Deterding (Eds.), The gameful world: Approaches, issues, applications, (pp. 139-161). Cambridge: MIT Press.

Hamari, J., Koivisto, J., \& Sarsa, H. (2014). Does gamification work? - A literature review of empirical studies on gamification. In Proceedings of the 47th Hawaii international conference on system sciences (HICSS 2014).. Hawaii: IEEE Computer Society Press. pp. 3025-34.

Hsee, C. K., Yu, F., Zhang, J., \& Zhang, Y. (2003). Medium maximization. Journal of Consumer Research, 30(1), 1-14. 
Huotari, K., \& Hamari, J. (2017). A definition for gamification: Anchoring gamification in the service marketing literature. Electronic Markets, 27(1), 21-31.

Landers, R. N., Tondello, G. F., Kappen, D. L., Collmus, A. B., Mekler, E. D., \& Nacke, L. E. (2018). Defining gameful experience as a psychological state caused by gameplay: Replacing the term 'Gamefulness' with three distinct constructs. International Journal of Human Computing Studies, 127, 81-94.

Lister, C., West, J. H., Cannon, B., Sax, T., \& Brodegard, D. (2014). Just a fad? Gamification in health and fitness apps, JMIR Serious Games, 2. JMIR Publications. https://doi.org/10.2196/games.3413.

Loboda, T. D., Guerra, J., Hosseini, R., \& Brusilovsky, P. (2014). Mastery Grids: an open source social educational progress visualization. In: C. Rensing, S. de Freitas, T. Ley, P.J. Muñoz-Merino (Eds.) Open learning and teaching in educational communities, proceedings of the 9th European Conference on Technology Enhanced Learning (EC-TEL 2014). Graz, Austria, 2014, LNCS, 8719: Springer. p. 235-48.

Lopez, C., \& Tucker, C. S. (2019). Implementing gamification in engineering bridge programs: A case study exploring the use of the Kahoot! Application. In Proceedings of ASEE zone 1 conference. Buffalo: IEEE.

Marczewski, A. (2015). User types. In Even ninja monkeys like to play: Gamification, Game Thinking \& Motivational Design, (pp. 69-84). CreateSpace Independent Publishing Platform.

McCoach, D. B., \& Siegle, D. (2003). Factors that differentiate underachieving gifted students from high-achieving gifted students. The Gifted Child Quarterly, 47(2), 144-154.

Michie, S., van Stralen, M. M., \& West, R. (2011). The behaviour change wheel: A new method for characterising and designing behaviour change interventions. Implementation Science, 6, 42.

Mora, A., Tondello, G. F., Calvet, L., González, C. S., Arnedo-Moreno, J., \& Nacke, L. E. (2019). The quest for a better tailoring of gameful design: An analysis of player type preferences. In Proceedings of the XX international conference on human computer interaction (Interacción 2019), (pp. 1-8). Donostia Gipuzkoa. https://doi.org/10.1145/3335595.3335625.

Myers, I. B. (1962). The Myers-Briggs type indicator. Palo Alto: Consulting Psychologists Press.

Nacke, L. E., Bateman, C., \& Mandryk, R. L. (2014). BrainHex: A neurobiological gamer typology survey. Entertainment Computing, 5(1), 55-62. https://doi.org/10.1016/j.entcom.2013.06.002.

Nicholson, S. (2015). A recipe for meaningful gamification. In L. Wood, \& T. Reiners (Eds.), Gamification in education and business. New York: Springer.

Orji, R., Tondello, G. F., \& Nacke, L. E. (2018). Personalizing persuasive strategies in Gameful systems to gamification user types. In Proceedings of the SIGCHI Conference on Human Factors in Computing Systems - CHI '18 ACM.

Richards, C., Thompson, C. W., \& Graham, T. C. N. (2014). Beyond designing for motivation: The im-portance of context in gamification. In Proceedings of the first ACM SIGCHI annual symposium on computer-human interaction in play, (pp. 217-226). New York: ACM.

Rigby, S. (2014). Gamification and motivation. In S. P. Walz, \& S. Deterding (Eds.), The Gameful world: Approaches, issues, applications, (pp. 113-137). Cambridge: MIT Press.

Rothrock, K. E., \& Freivalds, L. (2018). A. an empirical study on the impact of lab gamification on engineering students' satisfaction and learning. International Journal of Engineering Education, 34(1), 201-216.

Ryan, R. M., \& Deci, E. L. (2000). Intrinsic and extrinsic motivations: Classic definitions and new directions. Contemporary Educational Psychology, 25(1), 54-67. https://doi.org/10.1006/ceps.1999.1020.

Tondello, G. F., Mora, A., Marczewski, A., \& Nacke, L. E. (2018). Empirical validation of the gamification user types Hexad scale in English and Spanish. International Journal of Human Computer Studies, 127, 95-111.

Tondello, G. F., Wehbe, R. R., Diamond, L., Busch, M., Marczewski, A., \& Nacke, L. E. (2016). The gamification user types Hexad scale. In Proceedings of the 2016 annual symposium on computer-human interaction in play, (pp. 229-243). Austin: ACM.

WEKA (2020). The workbench for machine learning Accessed from https://www.cs.waikato.ac.nz/ml/weka/.

Wigfield, A., \& Cambria, J. (2010). Expectancy-value theory: Retrospective and prospective. In C. Urdan, \& S. A. Karabenick (Eds.), The decade ahead: Theoretical perspectives on motivation and achievement (advances in motivation and achievement), volume 16, (pp. 74-146).

Yee, N. (2015). Gamer motivation model overview and descriptions Quantic Foundry. http://quanticfoundry.com/2015/12/15/ handy-reference/.

Zhang, P. (2008). Motivational affordances: Reasons for ICT design and use. Communications of the ACM, 51(11), 145-147.

\section{Publisher's Note}

Springer Nature remains neutral with regard to jurisdictional claims in published maps and institutional affiliations.

\section{Submit your manuscript to a SpringerOpen ${ }^{\circ}$ journal and benefit from:}

- Convenient online submission

- Rigorous peer review

- Open access: articles freely available online

High visibility within the field

- Retaining the copyright to your article

Submit your next manuscript at $\boldsymbol{\nabla}$ springeropen.com 